\title{
Separation of Ethyl Acetate and 2-propanol Azeotropic Mixture using Ionic Liquids as
}

\section{Entrainers}

\author{
Zhigang Zhang, Aidi Zhang, Kaifang Wu, Qinqin Zhang,* Angran Hu, Wenxiu Li*
}

Liaoning Provincial Key Laboratory of Chemical Separation Technology, Shenyang University of Chemical Technology, Shenyang 110142 , China.

\begin{abstract}
Ionic liquids (ILs) as entrainers for the separation of ethyl acetate and 2-propanol azeotropic mixture were proposed in this work. Through the isobaric vapor-liquid equilibrium (VLE) experiments, we found that the three investigated ILs, namely 1-butyl-3-methylimidazolium acetate ([BMIM][Ac]), 1-butyl-3-methylimidazolium bromide ([BMIM][Br]), and 1-butyl-3-methylimidazolium tetrafluoroborate ([BMIM] $\left[\mathrm{BF}_{4}\right]$ ), could significantly enhance the separation factor of ethyl acetate and 2-propanol, and eliminate the azeotropic point. [BMIM][Ac] produced the most notable salting-out effect on ethyl acetate and 2-propanol among the three investigated ILs. Moreover, the experimental data were well correlated with the non-random two liquid (NRTL) model. Finally, $\sigma$-Profiles of solvents and ILs were used to explain the different separate abilities of the three investigated ILs.
\end{abstract}

Keywords: ionic liquids, vapor-liquid equilibrium, ethyl acetate, 2-propanol, NRTL model, $\sigma$-Profiles

* Corresponding Author: Wenxiu Li, Email address: wenxli@ 126.com, Fax: 86-24-89383736; 


\section{Introduction}

Separation of azeotropes or close-boiling point mixtures is a challenging task since simple distillation is inadequate to complete it. In this situation, extractive distillation has been used widely in industry for its advantages such as high separation efficiency, easy operation and high capacity. [1] In extractive distillation, the addition of an entrainer improves the separation factor (relative volatility), thus achieving the desired separation. [2] Therefore, the selection of an efficient and suitable entrainer is of great importance. [3-4] Conventional organic solvents as entrainers have many disadvantages, such as huge energy consumption as well as environmental pollution. [5] Inorganic salts as entrainers may corrode the pipes and facilities, their solvent capacities are limited and their reuse is difficult. Nowadays, ionic liquids have attracted much attention as efficient entrainers in extractive distillation because of their distinct advantages, such as negligible vapor pressure, being liquid at room temperature, good thermal and chemical stability, high separation ability, and tunable structure. [6-9] It was suggested that ILs as entrainers in extractive distillation integrate the advantages of a liquid solvent (easy operation) and a solid salt (high separation ability). [10-11] Besides, they are easy to be recovered by simple distillation since ILs have negligible vapor pressure. [12]

As important chemical raw materials and organic solvents, ethyl acetate and 2-propanol occupy significant position in industry. Ethyl acetate has been applied to many promising applications [13] for its excellent solubility and quick - drying property. 2-propanol is widely used in medicine, organic synthesis and other industries. [14] The mixture of ethyl acetate and 2-propanol can be found in the solvent extraction of edible oils. [15] If this mixture cannot be effectively separated, it will bring about environmental pollution as well as a waste of resource. As ethyl acetate and 2-propanol form an azeotrope at atmospheric pressure, it is impossible to separate them by simple distillation. As mentioned above, ionic liquids are promising entrainers for the separation of azeotropic mixtures by extractive distillation. To our knowledge, there are few researches about the separation of ethyl acetate and 2-propanol mixture. Most of them are pressure-swing distillation, including the isobaric vapor-liquid equilibrium experiment at $0.3 \mathrm{MPa}, 0.6 \mathrm{MPa}$ 
by Susial et al. [16], and at $1.5 \mathrm{MPa}$ by Susial et al. [17]. Pereiro et al. [18] measured the ternary liquid-liquid equilibrium data of ethyl acetate + 2-propanol with 1, 3-dimethylimidazolium methyl sulfate $\left([\mathrm{MMIM}]\left[\mathrm{MeSO}_{4}\right]\right)$ or 1 -butyl-3-methylimidazolium hexafluorophosphate $\quad\left([\mathrm{BMIM}]\left[\mathrm{PF}_{6}\right]\right)$ or 1-hexyl-3-methylimidazolium hexafluorophosphate $\left([\mathrm{HMIM}]\left[\mathrm{PF}_{6}\right]\right)$, revealing that ILs can be used as solvents to separate the system by extraction. Shi et al. [19] studied the separation of ethyl acetate + 2-propanol by extractive distillation with 1-octyl-3-methylimidazolium tetrafluoroborate ([OMIM][BF 4$])$ as the extraction agent at $101.32 \mathrm{kPa}$, illustrating that $[\mathrm{OMIM}]\left[\mathrm{BF}_{4}\right]$ can break the azeotropic point and the proper mole fraction of $[\mathrm{OMIM}]\left[\mathrm{BF}_{4}\right]$ is about $20 \%$.

In this work, three ionic liquids, namely 1-butyl-3-methylimidazolium acetate ([BMIM][Ac]), 1-butyl-3-methylimidazolium bromide ([BMIM][Br]), and 1-butyl-3-methylimidazolium tetrafluoroborate ([BMIM] $\left[\mathrm{BF}_{4}\right]$ ), were chosen as the new entrainers to separate the ethyl acetate and 2-propanol azeotropic mixture. Firstly, the VLE data of the ternary system of ethyl acetate + 2-propanol + IL were measured at 101.3 $\mathrm{kPa}$. The separation effect of the three ILs was discussed and compared in terms of separation factor. The selected ILs have the same cation but different anions, which will promote the understanding of structure-property relationship. Then, the non-random two liquid (NRTL) model [20] was used to correlate ternary VLE data and the model parameters were obtained. Finally, the $\sigma$-Profiles of solvents and ILs, which were calculated by COSMO-SAC model [21-23], were used to analysis the separation mechanism at the molecular level.

\section{Experimental section}

\subsection{Material}

Ethyl acetate (> 99.9\% in mass fraction) and 2-propanol (>99.9\% in mass fraction) were purchased from Sinopharm group. The ILs [BMIM][Ac], [BMIM][Br], and [BMIM][BF 4 ] were synthesized, purified, and dried in a vacuum drying oven according to the reported methods. [24-25] The purities of the three ILs are at least $98 \%$ in mass fraction detected by liquid chromatography and the water content of ILs is less than 
0.005 in mass fraction detected by Karl Fischer titration. The specifications of the chemicals used in this work are summarized in Table 1.

\section{Table 1}

The specifications of chemical samples.

\begin{tabular}{llllll}
\hline Chemical name & CAS RN & Source & purity & Purification method & Analysis method \\
\hline ethyl acetate & $141-78-6$ & SinopharmGroup & 0.999 & None & $\mathrm{GC}^{\mathrm{d}}$ \\
2-propanol & $67-63-0$ & SinopharmGroup & 0.999 & None & $\mathrm{GC}^{\mathrm{d}}$ \\
[BMIM][Ac] $^{\text {a }}$ & $284049-75-8$ & Prepared in this work & 0.980 & Vacuum desiccation & $\mathrm{LC}^{\mathrm{e}} \mathrm{KF}^{\mathrm{f}}$ \\
{$[\mathrm{BMIM}][\mathrm{Br}]^{\text {b }}$} & $85100-77-2$ & Prepared in this work & 0.980 & Vacuum desiccation & $\mathrm{LC}^{\mathrm{e}} \mathrm{KF}^{\mathrm{f}}$ \\
$\left.[\mathrm{BMIM}][\mathrm{BF}]_{4}\right]^{\mathrm{c}}$ & $174501-65-6$ & Prepared in this work & 0.980 & Vacuum desiccation & $\mathrm{LC}^{\mathrm{e}} \mathrm{KF}^{\mathrm{f}}$ \\
\hline
\end{tabular}

${ }^{\mathrm{a}}[\mathrm{BMIM}][\mathrm{Ac}]=1$-butyl-3-methylimidazolium acetate

${ }^{\mathrm{b}}[\mathrm{BMIM}][\mathrm{Br}]=$ 1-butyl-3-methylimidazolium bromide

${ }^{\mathrm{c}}[\mathrm{BMIM}]\left[\mathrm{BF}_{4}\right]=$ 1-butyl-3-methylimidazolium tetrafluoroborate

${ }^{\mathrm{d}} \mathrm{GC}=$ gas chromatography.

${ }^{\mathrm{e}} \mathrm{LC}=$ liquid chromatography.

${ }_{\mathrm{f}}^{\mathrm{f}} \mathrm{KF}=$ Karl Fischer titration.

\subsection{Apparatus and procedure}

An all-glass equilibrium still (NGW, Wertheim, Germany) was employed to conduct the vapor-liquid equilibrium experiments, which has been described in detail in previous publication. [26] The pressure of the system was maintained at $101.3 \mathrm{kPa}$ by controlling a gas buffer connected with the still, and measured by a manometer with a standard uncertainty of $0.10 \mathrm{kPa}$. The system temperature was measured using a standard and calibrated thermometer with an uncertainty of $0.01 \mathrm{~K}$. The equilibrium state was assumed when the temperature was constant for more than 30 minutes. Then the condensed vapor and liquid samples were taken out and analyzed. The samples were placed in a headspace sampler (HS-sampler) (G1888 Network headspace sampler, Agilent Technologies) and then detected by a gas chromatograph (Model 7890A, Agilent Technologies) equipped with a SP-1000 capillary column (30 m in length, $2.5 \mathrm{~mm}$ in diameter, and $2.5 \mathrm{~mm}$ in thickness) and a FID detector. The carrier gas was Nitrogen. The temperatures of oven, injector, and detector were $353 \mathrm{~K}, 423 \mathrm{~K}$, and $443 \mathrm{~K}$, respectively. Since ILs have negligible vapor pressure, only the peaks of ethyl acetate and 2-propanol were detected. The amount of ILs was gravimetrically determined by the mass difference before and after vaporizing the volatile components. The standard uncertainty of ILs 
components in vapor and liquid phases was 0.001 in mole fraction.

In this study, to obtain the $\sigma$-Profiles of ethyl acetate , 2-propanol and ILs, three procedures were performed. Firstly, all optimized geometries were obtained by minimizing the total energy of the molecule in the ideal gas phase (no imaginary frequency) using the density functional theory with the VWN-BP functional and version 4.0.0 DNP basis set by employing the DMol3 module implemented in MS. [27] Then, COSMO calculation was conducted to gain the parameters, such as the molecular volume, surface area and screening charges. [28] Finally, the .COSMO files were imported into the calculating software (Sigma-average_v2.exe) to obtain the data for $\sigma$-Profiles.

\section{Results and discussion}

\subsection{Experimental data}

The experimental VLE data for the ethyl acetate +2 -propanol system are listed in Table 2, which are compared with the reported data [29] and the data calculated by the NRTL model as depicted in Fig. 1. As the data measured in this work displays a good agreement with the others, we can get a conclusion that our apparatus is reliable to perform the VLE experiments for the systems containing ILs.

\section{Table 2}

Vapor-Liquid Equilibrium Data for Ethyl acetate (1) + 2-propanol (2) at $101.3 \mathrm{kPa}^{a}$

\begin{tabular}{|c|c|c|}
\hline$T / \mathrm{K}$ & $x_{1}$ & $y_{1}$ \\
\hline 355.39 & 0.000 & 0.000 \\
\hline 353.21 & 0.094 & 0.158 \\
\hline 351.35 & 0.197 & 0.292 \\
\hline 350.68 & 0.243 & 0.347 \\
\hline 350.10 & 0.283 & 0.388 \\
\hline 349.31 & 0.369 & 0.463 \\
\hline 348.57 & 0.488 & 0.552 \\
\hline 348.21 & 0.565 & 0.606 \\
\hline 348.11 & 0.683 & 0.684 \\
\hline 348.09 & 0.709 & 0.710 \\
\hline 348.14 & 0.732 & 0.728 \\
\hline 348.18 & 0.764 & 0.753 \\
\hline 348.35 & 0.816 & 0.798 \\
\hline 349.31 & 0.942 & 0.924 \\
\hline 350.25 & 1.000 & 1.000 \\
\hline
\end{tabular}

${ }^{\mathrm{a}}$ Standard uncertainties $u$ are: $u(T)=0.05 \mathrm{~K} ; u\left(x_{1}\right)=u\left(y_{1}\right)=0.001$. 


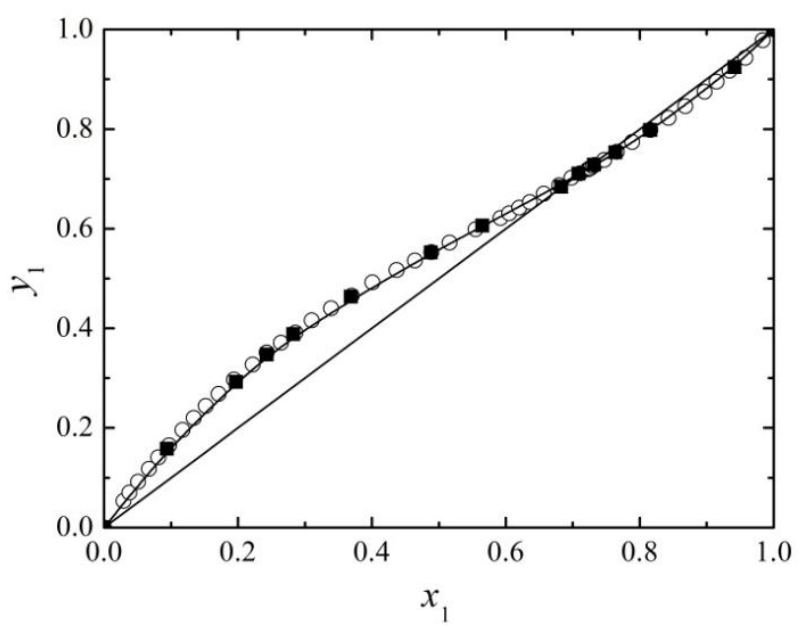

Fig. 1. Isobaric VLE data for the binary system of ethyl acetate (1) + 2-propanol (2) at $101.3 \mathrm{kPa}: \mathbf{\square}$, this work; O, ref [29]; solid line, correlated using the NRTL model.

As the total pressure is low $(101.3 \mathrm{kPa})$ in this work, the assumption of ideal vapor phase can be made, and the activity coefficient of component $i$ and the relative volatility can be calculated as follows:

$$
\begin{gathered}
\gamma_{i}=\frac{y_{i} P}{x_{i} P_{i}^{\mathrm{o}}} \\
\alpha_{12}=\frac{\gamma_{1} P_{1}^{\mathrm{o}}}{\gamma_{2} P_{2}^{\mathrm{o}}}
\end{gathered}
$$

where $y_{i}$ and $x_{i}$ are the mole fractions of component $i$ in the vapor phase and liquid phase, respectively, $\gamma_{i}$ is activity coefficient of component $i, P$ is the total pressure, $P_{i}^{\circ}$ refers to the saturated pressure of component $i$ at equilibrium temperature which is calculated by Antoine equation with the Antoine parameters taken from previous literature [29].

By keeping the mole fraction of ILs nearly constant at 0.10, 0.20 and 0.30, the ternary VLE data were measured. The experimental results are provided in Tables 3 to 5, where $x_{3}$ is the mole fraction of IL, $T$ is the experimental temperature, $x_{1}$ is the liquid-phase mole fraction of ethyl acetate containing IL, $x_{1}^{\prime}$ is the liquid-phase mole fraction of ethyl acetate excluding IL, $y_{1}$ is the gas-phase mole fraction of ethyl acetate, and $\alpha_{12}$ is the relative volatility of ethyl acetate to 2-propanol. 
Table 3

Vapor-liquid equilibrium data for ethyl acetate (1) + 2-propanol (2) + [BMIM][Ac] (3) at $101.3 \mathrm{kPa}^{a}$

\begin{tabular}{llllllllllll}
\hline$x_{3}$ & $T / \mathrm{K}$ & $x_{1}$ & $x_{1}^{\prime}$ & $y_{1}$ & $\alpha_{12}$ & $x_{3}$ & $T / \mathrm{K}$ & $x_{1}$ & $x_{1}^{\prime}$ & $y_{1}$ & $\alpha_{12}$ \\
\hline 0.100 & 357.70 & 0.002 & 0.002 & 0.005 & 2.290 & 0.200 & 354.89 & 0.564 & 0.705 & 0.837 & 2.148 \\
0.100 & 356.25 & 0.073 & 0.081 & 0.164 & 2.219 & 0.198 & 354.72 & 0.609 & 0.759 & 0.867 & 2.066 \\
0.099 & 355.75 & 0.103 & 0.114 & 0.221 & 2.195 & 0.200 & 354.55 & 0.664 & 0.830 & 0.907 & 1.998 \\
0.100 & 355.16 & 0.150 & 0.166 & 0.298 & 2.129 & 0.199 & 354.39 & 0.703 & 0.878 & 0.932 & 1.911 \\
0.101 & 354.59 & 0.201 & 0.224 & 0.377 & 2.101 & 0.201 & 354.29 & 0.731 & 0.915 & 0.953 & 1.886 \\
0.100 & 354.10 & 0.249 & 0.277 & 0.437 & 2.025 & 0.299 & 362.80 & 0.028 & 0.040 & 0.117 & 3.180 \\
0.100 & 353.78 & 0.293 & 0.325 & 0.488 & 1.976 & 0.300 & 361.63 & 0.066 & 0.095 & 0.250 & 3.190 \\
0.101 & 353.19 & 0.399 & 0.444 & 0.593 & 1.827 & 0.301 & 360.62 & 0.105 & 0.150 & 0.362 & 3.215 \\
0.098 & 352.72 & 0.517 & 0.573 & 0.690 & 1.661 & 0.298 & 359.31 & 0.164 & 0.234 & 0.493 & 3.190 \\
0.100 & 352.61 & 0.605 & 0.672 & 0.761 & 1.554 & 0.299 & 358.54 & 0.212 & 0.302 & 0.579 & 3.179 \\
0.101 & 352.52 & 0.725 & 0.806 & 0.852 & 1.385 & 0.300 & 358.07 & 0.247 & 0.354 & 0.633 & 3.153 \\
0.100 & 352.50 & 0.757 & 0.841 & 0.875 & 1.319 & 0.302 & 357.43 & 0.308 & 0.441 & 0.712 & 3.130 \\
0.100 & 352.51 & 0.835 & 0.928 & 0.942 & 1.263 & 0.300 & 356.97 & 0.359 & 0.513 & 0.764 & 3.076 \\
0.198 & 360.16 & 0.016 & 0.020 & 0.051 & 2.708 & 0.301 & 356.64 & 0.400 & 0.572 & 0.802 & 3.028 \\
0.201 & 359.53 & 0.046 & 0.057 & 0.142 & 2.719 & 0.300 & 356.14 & 0.479 & 0.684 & 0.863 & 2.906 \\
0.199 & 358.43 & 0.097 & 0.121 & 0.269 & 2.661 & 0.302 & 355.92 & 0.514 & 0.736 & 0.889 & 2.867 \\
0.200 & 357.05 & 0.194 & 0.243 & 0.454 & 2.597 & 0.300 & 355.58 & 0.564 & 0.806 & 0.920 & 2.773 \\
0.201 & 356.23 & 0.281 & 0.351 & 0.577 & 2.517 & 0.299 & 355.19 & 0.615 & 0.877 & 0.950 & 2.657 \\
0.200 & 355.65 & 0.369 & 0.462 & 0.674 & 2.409 & 0.300 & 354.74 & 0.666 & 0.951 & 0.981 & 2.636 \\
0.202 & 355.30 & 0.455 & 0.570 & 0.754 & 2.310 & & & & & & \\
\hline
\end{tabular}

${ }^{a}$ Standard uncertainties $u$ are $u(T)=0.05 \mathrm{~K}, u(P)=0.1 \mathrm{kPa}, u\left(x_{3}\right)=u\left(x_{1}\right)=u\left(x_{1}^{\prime}\right)=u\left(y_{1}\right)=0.001$. 
Table 4

Vapor-liquid equilibrium data for ethyl acetate (1) + 2-propanol (2) + [BMIM][Br] (3) at $101.3 \mathrm{kPa}^{a}$

\begin{tabular}{llllllllllll}
\hline$x_{3}$ & $T / K$ & $x_{1}$ & $x_{1}^{\prime}$ & $y_{1}$ & $\alpha_{12}$ & $x_{3}$ & $T / K$ & $x_{1}$ & $x_{1}^{\prime}$ & $y_{1}$ & $\alpha_{12}$ \\
\hline 0.100 & 356.57 & 0.040 & 0.045 & 0.095 & 2.228 & 0.201 & 355.56 & 0.347 & 0.434 & 0.644 & 2.359 \\
0.099 & 356.34 & 0.068 & 0.075 & 0.152 & 2.213 & 0.202 & 355.14 & 0.429 & 0.538 & 0.722 & 2.230 \\
0.100 & 355.65 & 0.111 & 0.123 & 0.231 & 2.143 & 0.202 & 354.90 & 0.493 & 0.618 & 0.776 & 2.141 \\
0.100 & 355.09 & 0.148 & 0.165 & 0.296 & 2.129 & 0.202 & 354.68 & 0.565 & 0.708 & 0.833 & 2.057 \\
0.101 & 354.50 & 0.204 & 0.227 & 0.375 & 2.043 & 0.202 & 354.48 & 0.635 & 0.796 & 0.881 & 1.897 \\
0.101 & 353.69 & 0.297 & 0.331 & 0.490 & 1.943 & 0.203 & 354.30 & 0.698 & 0.875 & 0.928 & 1.841 \\
0.099 & 353.18 & 0.371 & 0.412 & 0.560 & 1.817 & 0.203 & 354.21 & 0.727 & 0.912 & 0.949 & 1.795 \\
0.101 & 352.65 & 0.534 & 0.594 & 0.703 & 1.620 & 0.291 & 361.77 & 0.057 & 0.080 & 0.209 & 3.039 \\
0.102 & 352.56 & 0.606 & 0.675 & 0.759 & 1.514 & 0.299 & 361.50 & 0.073 & 0.104 & 0.264 & 3.090 \\
0.099 & 352.41 & 0.657 & 0.729 & 0.793 & 1.426 & 0.299 & 360.21 & 0.123 & 0.175 & 0.394 & 3.065 \\
0.100 & 352.42 & 0.705 & 0.783 & 0.830 & 1.350 & 0.300 & 359.18 & 0.172 & 0.245 & 0.497 & 3.045 \\
0.102 & 352.51 & 0.799 & 0.890 & 0.920 & 1.426 & 0.300 & 358.37 & 0.220 & 0.314 & 0.580 & 3.017 \\
0.100 & 352.56 & 0.867 & 0.963 & 0.969 & 1.190 & 0.300 & 357.70 & 0.270 & 0.386 & 0.652 & 2.980 \\
0.199 & 359.53 & 0.043 & 0.054 & 0.131 & 2.641 & 0.300 & 357.08 & 0.328 & 0.469 & 0.720 & 2.911 \\
0.199 & 359.04 & 0.066 & 0.082 & 0.190 & 2.626 & 0.301 & 356.61 & 0.384 & 0.549 & 0.776 & 2.846 \\
0.200 & 358.70 & 0.082 & 0.103 & 0.231 & 2.616 & 0.301 & 356.09 & 0.457 & 0.654 & 0.838 & 2.737 \\
0.200 & 358.09 & 0.116 & 0.145 & 0.306 & 2.600 & 0.301 & 355.75 & 0.511 & 0.731 & 0.878 & 2.648 \\
0.201 & 357.51 & 0.152 & 0.190 & 0.376 & 2.569 & 0.302 & 355.37 & 0.568 & 0.813 & 0.918 & 2.575 \\
0.201 & 356.89 & 0.197 & 0.247 & 0.453 & 2.525 & 0.302 & 355.05 & 0.612 & 0.877 & 0.945 & 2.410 \\
0.201 & 356.25 & 0.257 & 0.322 & 0.540 & 2.472 & 0.302 & 354.82 & 0.643 & 0.921 & 0.967 & 2.514 \\
\hline
\end{tabular}

${ }^{a}$ Standard uncertainties $u$ are $u(T)=0.05 \mathrm{~K}, u(P)=0.1 \mathrm{kPa}, u\left(x_{3}\right)=u\left(x_{1}\right)=u\left(x_{1}^{\prime}\right)=u\left(y_{1}\right)=0.001$. 
Table 5

Vapor-liquid equilibrium data for ethyl acetate (1) + 2-propanol (2) + [BMIM] $\left[\mathrm{BF}_{4}\right](3)$ at $101.3 \mathrm{kPa}^{a}$

\begin{tabular}{llllllllllll}
\hline$x_{3}$ & $T / K$ & $x_{1}$ & $x_{1}^{\prime}$ & $y_{1}$ & $\alpha_{12}$ & $x_{3}$ & $T / K$ & $x_{1}$ & $x_{1}^{\prime}$ & $y_{1}$ & $\alpha_{12}$ \\
\hline 0.101 & 355.71 & 0.071 & 0.079 & 0.156 & 2.155 & 0.201 & 355.39 & 0.315 & 0.394 & 0.570 & 2.039 \\
0.101 & 355.17 & 0.126 & 0.140 & 0.252 & 2.070 & 0.200 & 355.12 & 0.360 & 0.450 & 0.615 & 1.952 \\
0.103 & 354.69 & 0.163 & 0.182 & 0.310 & 2.019 & 0.200 & 354.65 & 0.507 & 0.634 & 0.744 & 1.678 \\
0.102 & 354.13 & 0.211 & 0.235 & 0.373 & 1.937 & 0.200 & 354.54 & 0.551 & 0.689 & 0.779 & 1.591 \\
0.101 & 353.49 & 0.278 & 0.309 & 0.452 & 1.844 & 0.200 & 354.47 & 0.596 & 0.745 & 0.816 & 1.518 \\
0.100 & 353.15 & 0.321 & 0.357 & 0.494 & 1.758 & 0.200 & 354.40 & 0.633 & 0.791 & 0.846 & 1.452 \\
0.102 & 352.68 & 0.423 & 0.471 & 0.589 & 1.610 & 0.200 & 354.35 & 0.664 & 0.830 & 0.873 & 1.408 \\
0.101 & 352.36 & 0.517 & 0.575 & 0.664 & 1.461 & 0.201 & 354.33 & 0.690 & 0.864 & 0.896 & 1.361 \\
0.103 & 352.28 & 0.578 & 0.644 & 0.712 & 1.367 & 0.301 & 361.12 & 0.052 & 0.075 & 0.186 & 2.818 \\
0.101 & 352.18 & 0.654 & 0.728 & 0.770 & 1.251 & 0.302 & 360.64 & 0.069 & 0.099 & 0.235 & 2.796 \\
0.102 & 352.20 & 0.694 & 0.773 & 0.803 & 1.197 & 0.302 & 359.74 & 0.103 & 0.148 & 0.323 & 2.747 \\
0.100 & 352.19 & 0.754 & 0.838 & 0.852 & 1.113 & 0.300 & 358.97 & 0.139 & 0.198 & 0.395 & 2.645 \\
0.100 & 352.32 & 0.817 & 0.908 & 0.910 & 1.024 & 0.306 & 358.35 & 0.181 & 0.261 & 0.476 & 2.572 \\
0.101 & 352.55 & 0.871 & 0.969 & 0.967 & 0.937 & 0.301 & 357.74 & 0.223 & 0.319 & 0.538 & 2.486 \\
0.200 & 358.74 & 0.054 & 0.068 & 0.155 & 2.514 & 0.302 & 357.05 & 0.297 & 0.426 & 0.633 & 2.324 \\
0.200 & 358.10 & 0.083 & 0.104 & 0.223 & 2.473 & 0.304 & 356.63 & 0.363 & 0.521 & 0.702 & 2.166 \\
0.202 & 357.60 & 0.112 & 0.140 & 0.284 & 2.437 & 0.302 & 356.30 & 0.422 & 0.604 & 0.754 & 2.010 \\
0.201 & 357.14 & 0.139 & 0.174 & 0.333 & 2.370 & 0.300 & 355.93 & 0.498 & 0.712 & 0.821 & 1.855 \\
0.201 & 356.72 & 0.169 & 0.211 & 0.382 & 2.311 & 0.308 & 355.83 & 0.529 & 0.765 & 0.853 & 1.783 \\
0.200 & 356.27 & 0.204 & 0.255 & 0.435 & 2.249 & 0.305 & 355.53 & 0.586 & 0.843 & 0.899 & 1.658 \\
0.197 & 355.69 & 0.259 & 0.323 & 0.505 & 2.138 & 0.302 & 355.19 & 0.647 & 0.926 & 0.951 & 1.551 \\
\hline 5 & & & 0.354
\end{tabular}

${ }^{a}$ Standard uncertainties $u$ are $u(T)=0.05 \mathrm{~K}, u(P)=0.1 \mathrm{kPa}, u\left(x_{3}\right)=u\left(x_{1}\right)=u\left(x_{1}^{\prime}\right)=u\left(y_{1}\right)=0.001$.

3.2. Phase Equilibrium Model for the VLE Data.

The NRTL model was adopted to correlate the ternary VLE data because it has been reported to reproduce the experimental data of the IL-containing systems quite well. [30-34] The parameters for ethyl acetate (1) + 2-propanol (2) were first obtained from the IL-free binary VLE data, and other parameters corresponding to the solvents-IL were obtained from the ternary VLE data. The parameters were regressed with the aid of Levenberg-Marquardt method by minimizing objective function as below:

$$
A R D(\%)=\frac{1}{n} \sum_{n} \sum_{i}\left|\frac{\gamma_{i}^{\text {exptl }}-\gamma_{i}^{\text {calcd }}}{\gamma_{i}^{\text {exptl }}}\right| \times 100
$$

where $n$ is the number of experiment points, $\gamma_{i}$ refers to the activity coefficient of component $i$, and the superscripts "exptl" and "calcd" denote experimental and calculated values, respectively. The correlated 
results are listed in Table 6.

\section{Table 6}

Estimated values of nonrandomness factors, $\alpha_{\mathrm{ij}}$, and energy parameters $\Delta g_{\mathrm{ij}}$ and $\Delta g_{\mathrm{ji}}$ for NRTL model

\begin{tabular}{lllll} 
component $i$ & component $j$ & $\alpha_{i j}$ & $\frac{\Delta g_{i j}}{\mathrm{~J} / \mathrm{mol}}$ & $\frac{\Delta g_{j i}}{\mathrm{~J} / \mathrm{mol}}$ \\
\hline ethyl acetate & 2-propanol & 0.300 & 1676.0 & 40.8 \\
ethyl acetate & {$[\mathrm{BMIM}][\mathrm{Ac}]$} & 0.018 & 14588.8 & -7512.8 \\
2-propanol & {$[\mathrm{BMIM}][\mathrm{Ac}]$} & 0.541 & 532.1 & 24031.3 \\
ethyl acetate & {$[\mathrm{BMIM}][\mathrm{Br}]$} & 0.016 & 13249.3 & -6173.3 \\
2-propanol & {$[\mathrm{BMIM}][\mathrm{Br}]$} & 0.602 & 266.0 & 15311.4 \\
ethyl acetate & {$[\mathrm{BMIM}]\left[\mathrm{BF}_{4}\right]$} & 0.011 & 10745.0 & -4222.3 \\
2-propanol & {$[\mathrm{BMIM}]\left[\mathrm{BF}_{4}\right]$} & 0.461 & 1330.1 & 16818.9 \\
\hline
\end{tabular}

The mean absolute deviations and standard deviations between experimental and calculated values of the vapor-phase mole fractions and the equilibrium temperatures presented in Table 7 are small, indicating that the NRTL model fits the ternary VLE data quite well.

\section{Table 7}

Mean absolute deviations, $\delta y$ and $\delta T$, and standard deviations, $\sigma y$ and $\sigma T$, between experimental and calculated values of the vapor-phase mole fractions and the equilibrium temperatures

\begin{tabular}{lllll}
\hline system & $\delta y^{a}$ & $\sigma y^{b}$ & $\delta T^{c} / \mathrm{K}$ & $\sigma T^{d} / \mathrm{K}$ \\
\hline ethyl acetate + 2-propanol & 0.002 & 0.004 & 0.03 & 0.05 \\
ethyl acetate + 2-propanol + [BMIM] [Ac] & 0.004 & 0.005 & 0.21 & 0.24 \\
ethyl acetate + 2-propanol + [BMIM] [Br] & 0.003 & 0.005 & 0.26 & 0.30 \\
ethyl acetate + 2-propanol + [BMIM] $[\mathrm{BF} 4]$ & 0.005 & 0.006 & 0.32 & 0.37 \\
\hline${ }^{a} \delta y=(1 / n) \sum\left|y_{\text {exptl }}-y_{\text {calcd }}\right|{ }^{b} \sigma y=\left[\sum\left(y_{\text {exptl }}-y_{\text {calcd }}\right)^{2} /(n-m)\right]^{1 / 2} \cdot{ }^{c} \delta T=(1 / n) \sum\left|T_{\text {exptl }}-T_{\text {calcd }}\right|{ }^{d} \sigma T=\left[\sum\left(T_{\text {exptl }}-T_{\text {calcd }}\right)^{2} /(n-m)\right]^{1 / 2}$. \\
$n$ is the number of experimental points, and $m$ is the number of parameters for the model.
\end{tabular}

Figs 2 to 4 show the VLE diagrams for the ternary system of ethyl acetate (1) + 2-propanol (2) + ILs (3) at $101.3 \mathrm{kPa}$. It can be seen that the addition of ILs causes notable salting-out effect on ethyl acetate, and the azeotropic point is shifted upward with the content of ILs increase. The salting-out effect is more obvious as the concentration of IL becomes larger. The data calculated by NRTL model performed a good agreement with the experiment results. 


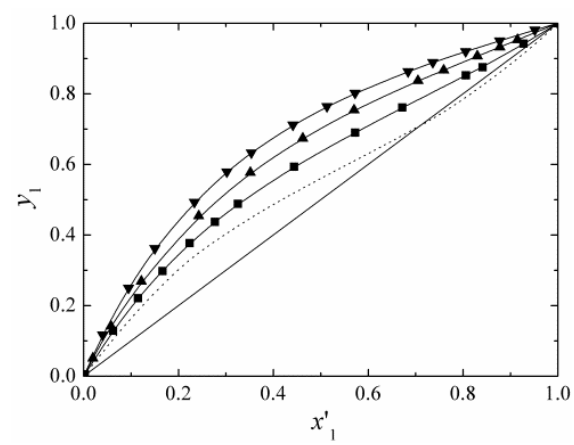

Fig. 2. VLE diagram for the ternary system of ethyl acetate (1) + 2-propanol (2) + [BMIM] [Ac] (3) at $101.3 \mathrm{kPa}$ : dotted line, IL-free system; घ, $x_{3}=0.10 ; \boldsymbol{\Delta}, x_{3}=0.20 ; \boldsymbol{\nabla}, x_{3}=$ 0.30; solid line, correlated using NRTL model.

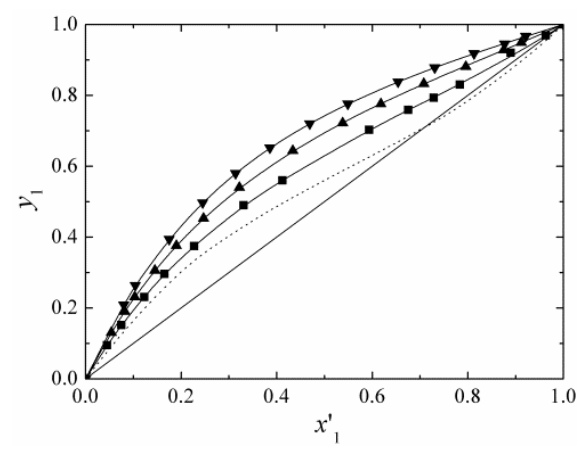

Fig. 3. VLE diagram for the ternary system of ethyl acetate (1) + 2-propanol (2) + [BMIM][Br] (3) at $101.3 \mathrm{kPa}$ : dotted line, IL-free system; घ, $x_{3}=0.10 ; \boldsymbol{\Delta}, x_{3}=0.20 ; \boldsymbol{\nabla}, x_{3}=$ 0.30; solid line, correlated using NRTL model.

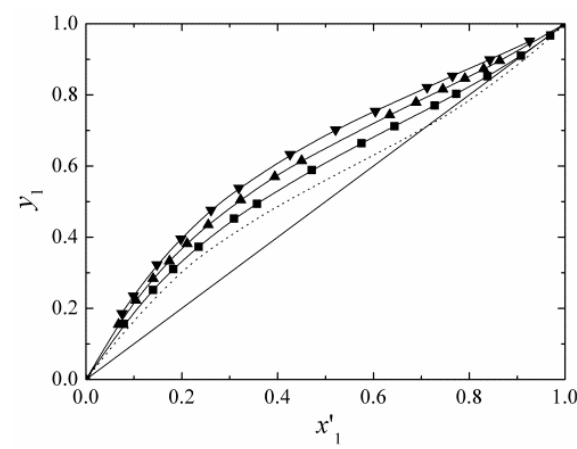

Fig. 4. VLE diagram for the ternary system of ethyl acetate (1) + 2-propanol (2) $+[\mathrm{BMIM}]\left[\mathrm{BF}_{4}\right]$ (3) at $101.3 \mathrm{kPa}$ : dotted line, IL-free system; $\mathbf{\square}, x_{3}=0.10 ; \boldsymbol{\Delta}, x_{3}=0.20 ; \boldsymbol{\nabla}, x_{3}=$ 0.30 ; solid line, correlated using NRTL model.

Figs 5 to 7 are the $T-x^{\prime}{ }_{1}-y_{1}$ diagrams for the ternary system of ethyl acetate (1) + 2-propanol (2) + ILs (3) at $101.3 \mathrm{kPa}$. From these we can see that the temperature of the system increase with the addition of ILs, and a displacement of the azeotropic point occurs. Moreover, the azeotrope disappears when the concentration of the ILs reach a certain value.

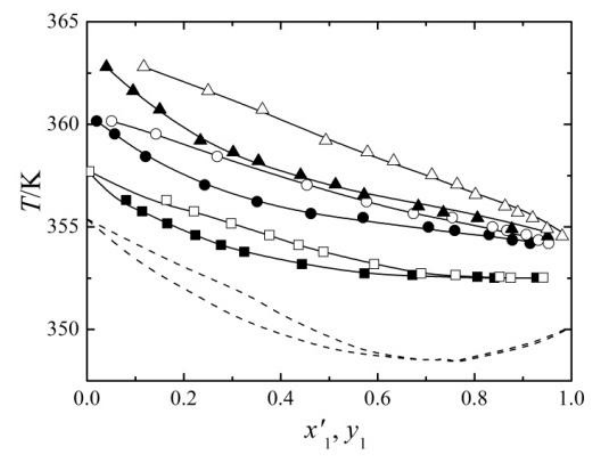

Fig. 5. $T-x^{\prime}{ }_{1}-y_{1}$ diagram for the ternary system of ethyl acetate (1) + 2-propanol (2) + [BMIM][Ac] (3) at $101.3 \mathrm{kPa}$ : dotted line, IL-free system; घ, $x_{1}^{\prime}\left(x_{3}=0.10\right) ; \square, y_{1}\left(x_{3}=0.10\right) ; \bullet$, $x_{1}^{\prime}\left(x_{3}=0.20\right)$; ○, $y_{1}\left(x_{3}=0.20\right) ; \boldsymbol{\Delta}, x_{1}^{\prime}$ $\left(x_{3}=0.30\right) ; \triangle, y_{1}\left(x_{3}=0.30\right)$; solid line, correlated using NRTL model.

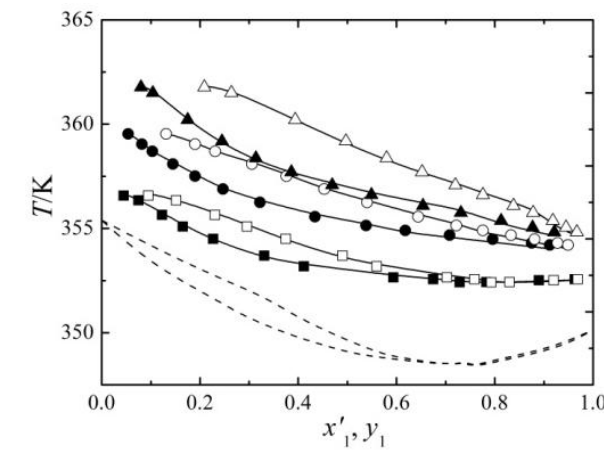

Fig. 6. $T-x^{\prime}{ }_{1}-y_{1}$ diagram for the ternary system of ethyl acetate (1) + 2-propanol (2) + [BMIM][Br] (3) at $101.3 \mathrm{kPa}$ : dotted line, IL-free system; घ, $x_{1}^{\prime}\left(x_{3}=0.10\right) ; \square, y_{1}\left(x_{3}=0.10\right) ; \bullet$, $x_{1}^{\prime}\left(x_{3}=0.20\right) ; \circ, y_{1}\left(x_{3}=0.20\right) ; \boldsymbol{\Delta}, x_{1}^{\prime}$ $\left(x_{3}=0.30\right) ; \triangle, y_{1}\left(x_{3}=0.30\right)$; solid line, correlated using NRTL model.

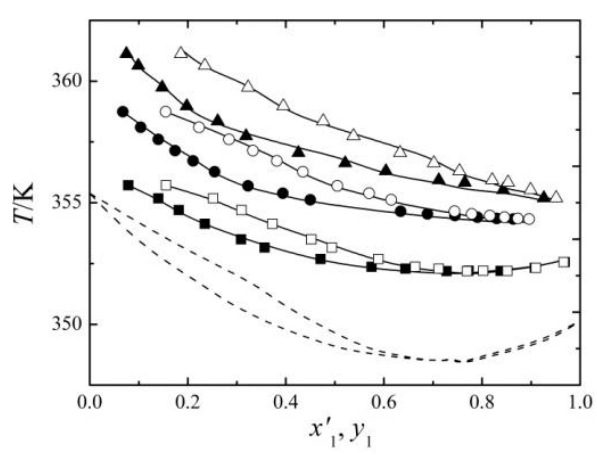

Fig. 7. $T-x^{\prime}{ }_{1}-y_{1}$ diagram for the ternary system of ethyl acetate (1) + 2-propanol (2) + [BMIM] $\left[\mathrm{BF}_{4}\right]$ (3) at $101.3 \mathrm{kPa}$ : dotted line, IL-free system; घ, $x_{1}^{\prime}\left(x_{3}=0.10\right) ; \square, y_{1}\left(x_{3}=0.10\right) ; \bullet$, $x_{1}^{\prime}\left(x_{3}=0.20\right) ; \circ, y_{1}\left(x_{3}=0.20\right) ; \boldsymbol{\Delta}, x_{1}^{\prime}$ $\left(x_{3}=0.30\right) ; \triangle, y_{1}\left(x_{3}=0.30\right)$; solid line, correlated using NRTL model.

Correspondingly, as illustrated in Figs 8 to 10, the relative volatility of ethyl acetate (1) to 2-propanol (2) increases with the addition of small amount of ILs. The more ILs, the higher the relative volatility. In addition, higher separation factor favors the separation process, since for a given purity of the distillate, the 
reflux ratio and the number of stages of the extractive distillation column can be reduced when the relative volatility of ethyl acetate to 2-propanol becomes higher. The salting-out effect produced by the three studied ILs follows the following sequence: $[\mathrm{BMIM}][\mathrm{Ac}]>[\mathrm{BMIM}][\mathrm{Br}]>[\mathrm{BMIM}]\left[\mathrm{BF}_{4}\right]$. The azeotropic point of ethyl acetate and 2-propanol tends to disappear when the content of ILs increase, indicating that the elimination of the azeotrope will be achieved when the amounts of ILs increase to a certain value.

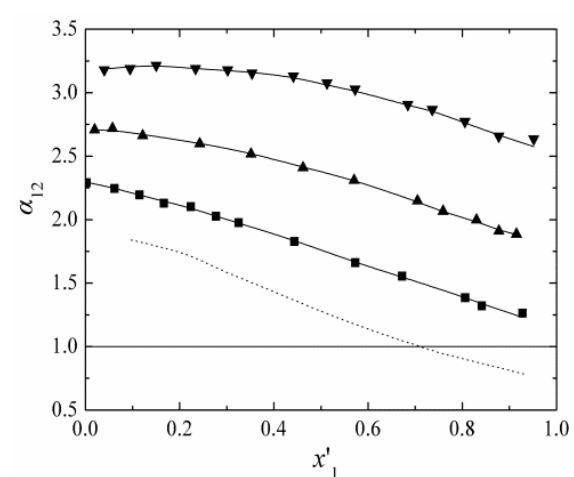

Fig. 8. Relative volatility of ethyl acetate to 2-propanol at different mole fraction of [BMIM][Ac] at $101.3 \mathrm{kPa}$ : dotted line, IL-free system; $\mathbf{\square}, x_{3}=0.10 ; \boldsymbol{\Delta}, x_{3}=$ $0.20 ; \boldsymbol{\nabla}, x_{3}=0.30 ;$ solid line, correlated using NRTL model.

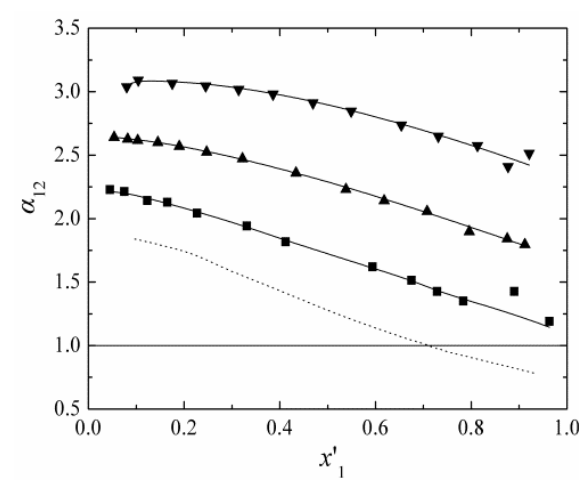

Fig. 9. Relative volatility of ethyl acetate to 2-propanol at different mole fraction of [BMIM][Br] at $101.3 \mathrm{kPa}:$ dotted line, IL-free system; $\mathbf{n}, x_{3}=0.10 ; \boldsymbol{\Delta}, x_{3}=$ $0.20 ; \boldsymbol{\nabla}, x_{3}=0.30$; solid line, correlated using NRTL model.

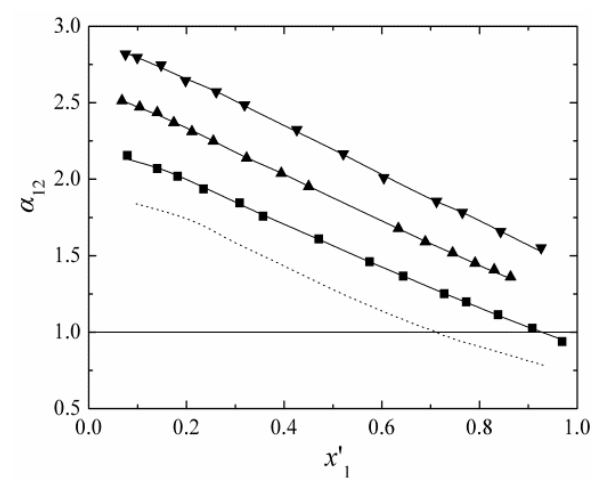

Fig. 10. Relative volatility of ethyl acetate to 2-propanol at different mole fraction of $[\mathrm{BMIM}]\left[\mathrm{BF}_{4}\right]$ at $101.3 \mathrm{kPa}$ : dotted line, IL-free system; $\mathbf{a}, x_{3}=0.10$; $\boldsymbol{\Delta}, x_{3}=0.20 ; \boldsymbol{\nabla}, x_{3}=0.30 ;$ solid line, correlated using NRTL model.

To provide a more intuitive view of the separation effect of the three ILs on the ethyl acetate and 2-propanol azeotropic mixture, the minimum mole fraction of $[\mathrm{BMIM}][\mathrm{Ac}],[\mathrm{BMIM}][\mathrm{Br}]$ and $[\mathrm{BMIM}]\left[\mathrm{BF}_{4}\right]$ needed to eliminate the azeotropic point has been calculated by NRTL model with the parameters listed in Table 6. To break the azeotrope, the minimum mole fraction of [BMIM][Ac] is 0.073, while those of $[\mathrm{BMIM}][\mathrm{Br}]$ and $[\mathrm{BMIM}]\left[\mathrm{BF}_{4}\right]$ are 0.079 and 0.136 , respectively. From these we can get a conclusion that among the three ILs, $[\mathrm{BMIM}][\mathrm{Ac}]$ perform better than $[\mathrm{BMIM}][\mathrm{Br}]$ and $[\mathrm{BMIM}]\left[\mathrm{BF}_{4}\right]$, and the specified order of the ILs is: $[\mathrm{BMIM}][\mathrm{Ac}]>[\mathrm{BMIM}][\mathrm{Br}]>[\mathrm{BMIM}]\left[\mathrm{BF}_{4}\right]$. 


\subsection{Analysis of the $\sigma$-Profiles}

As we all know, molecular interactions mainly consists of electrostatic interaction, hydrogen bonding and Vander Waals forces. [35] In this work, hydrogen bonding between solvents and ILs are discussed to explain the different effect of $[\mathrm{BMIM}][\mathrm{Ac}],[\mathrm{BMIM}][\mathrm{Br}]$ and $[\mathrm{BMIM}]\left[\mathrm{BF}_{4}\right]$ on the VLE behavior of ethyl acetate and 2-propanol. By analyzing the $\sigma$-Profiles, which can be calculated by COSMO-SAC model, the information that whether the hydrogen bond interaction between each molecules is strong or not can be obtained visually. [10, 35-39]The $\sigma$-Profiles of ethyl acetate and 2-propanol are shown in Fig 11, in which the vertical dashed lines represent the cutoff values of hydrogen bond effect $\left(\sigma<-0.0082 \mathrm{e} / \AA^{2}\right.$ represents the molecular have hydrogen bond donator ability, $\sigma>0.0082 \mathrm{e} / \AA^{2}$ represents the molecular have hydrogen bond acceptor ability, otherwise it is a nonpolar molecular). [38] As shown in Fig 11, the peaks of 2-propanol lie in both the left and right zone, while the peaks of ethyl acetate are only located in the right zone, which means that ethyl acetate only has hydrogen bond acceptor ability, while 2-propanol has both hydrogen bond acceptor and donator ability. As the three ILs have the same cation, the difference lie in the anions of ILs investigated, and the $\sigma$-Profiles of $[\mathrm{Ac}]^{-},[\mathrm{Br}]^{-}$and $\left[\mathrm{BF}_{4}\right]^{-}$anions are illustrated in Fig 12. It can be observed that the peaks of $[\mathrm{Ac}]^{-},[\mathrm{Br}]^{-}$and $\left[\mathrm{BF}_{4}\right]^{-}$anions are located in the $\sigma>0.0082 \mathrm{e} / \AA^{2}$ zone, showing that all of them have a strong hydrogen bond acceptor ability, which may play a primary role in increasing the relative volatility of ethyl acetate to 2-propanol via forming hydrogen bonds with 2-propanol. As the farther the peak from the right cutoff value of $\sigma$, the stronger is the hydrogen bond acceptor ability [36], so the hydrogen bond acceptor ability of the three ILs follow the order: $[\mathrm{Ac}]^{-}>[\mathrm{Br}]^{-}>\left[\mathrm{BF}_{4}\right]^{-}$. Thus the separate ability of the three ILs is $[\mathrm{BMIM}][\mathrm{Ac}]>[\mathrm{BMIM}][\mathrm{Br}]>[\mathrm{BMIM}]\left[\mathrm{BF}_{4}\right]$, showing a good agreement with the result of VLE experiment. 


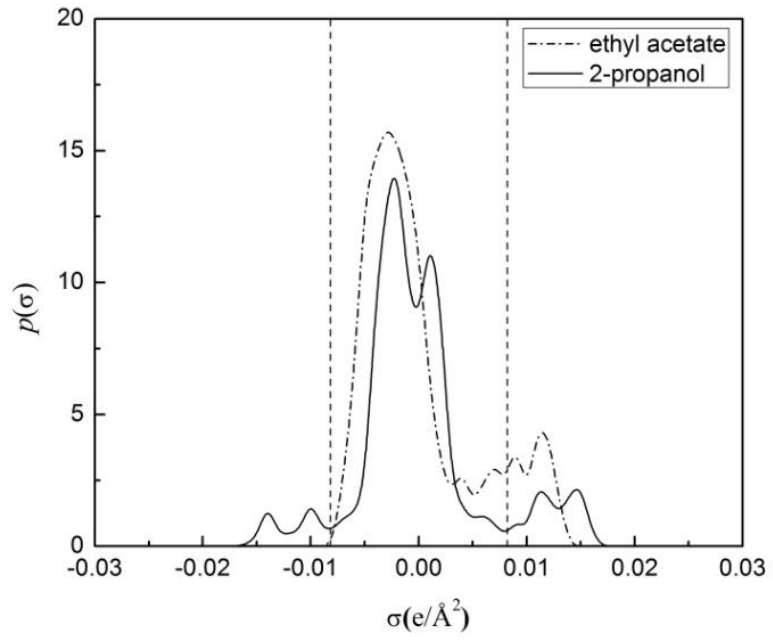

Fig.11. $\sigma$-Profiles for ethyl acetate and 2-propanol

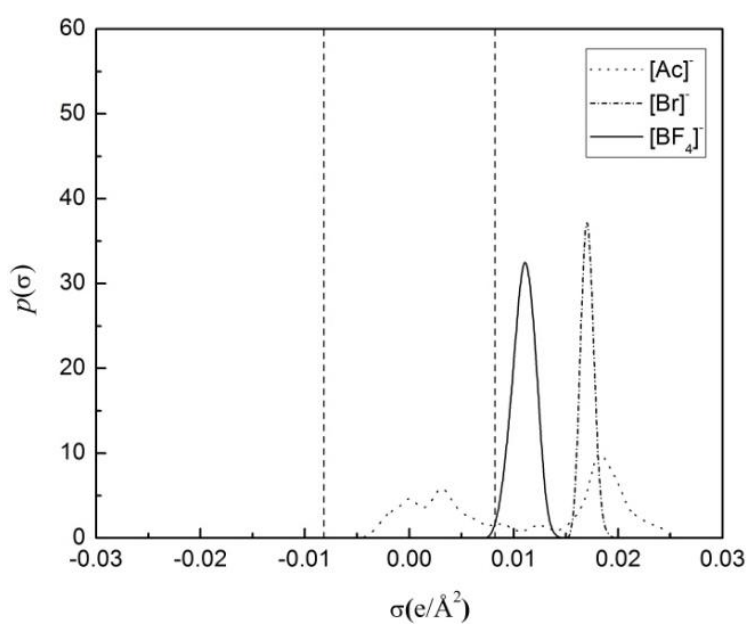

Fig.12. $\sigma$-Profiles for $[\mathrm{Ac}]^{-},[\mathrm{Br}]^{-}$and $\left[\mathrm{BF}_{4}\right]^{-}$anions

\section{Conclusions}

The capability of three ILs, namely $[\mathrm{BMIM}][\mathrm{Ac}],[\mathrm{BMIM}][\mathrm{Br}]$ and $[\mathrm{BMIM}]\left[\mathrm{BF}_{4}\right]$, as entertainers for the separation of ethyl acetate and 2-propanol system was investigated in this work. The results indicated that the addition of IL gave rise to the salting-out effect, and remarkably enhanced the relative volatility of ethyl acetate to 2-propanol. The salting-out effect produced by ILs was more notable as greater amount of ILs were added. All the three ILs have the potential to eliminate the azeotropic point of ethyl acetate and 2-propanol, moreover, [BMIM][Ac] outperforms the other two ILs. Besides, the measured VLE data were well correlated with NRTL model. Through the analysis of $\sigma$-Profiles, it is suggested that the strong hydrogen bonding interactions between ILs and 2-propanol weakens the interactions between ethyl acetate and 2-propanol, thus improving the relative volatility of ethyl acetate to 2-propanol. Thus, the $\sigma$-Profiles may be used to guide the selection of suitable entrainers for azeotrope separation in the future.

\section{Acknowledgement}

This work is financially supported by National Science Foundation of China (Project No. 21076126), National Science Foundation of China (Project No. 21576166), and Liaoning Province Science Foundation of China (Project No. 2014020140). 
$\Delta g_{\mathrm{ij}}$

$x_{\mathrm{i}}$

$y_{\mathrm{i}}$

$x_{\mathrm{i}}^{\prime}$

T

P

$P_{i}{ }^{\mathrm{O}}$

$n$

m

Greek letters

$\alpha_{12}$

$\alpha_{\mathrm{ij}}$

$\gamma_{i}$

$\delta y$

$\sigma y$

$\delta T$

$\sigma T$

$\sigma$

\section{References}

[1] Z. Lei, C. Li, B.Chen, Extractive Distillation: A Review, Sep. Purif. Rev. 32 (2003) 121-213.

[2] R. E. Treybal, Mass - Transfer Operations; McGraw Hill: New York. 1955.

[3] Z. Lei, B.Chen, Z. Ding, Special Distillation Processes; Elsevier: Amsterdam. 2005.

[4] Z. Zhang, D. Huang, M. Lv, P. Jia, D. Sun, W. Li, Entrainer selection for separating tetrahydrofuran/water azeotropic mixture by extractive distillation, Sep. Purif. Technol. 122 (2014) 73-77.

[5] Q. Li, J. Zhang, Z. Lei, J. Zhu, J. Zhu, X. Huang, Selection of Ionic Liquids as Entrainers for the Separation of Ethyl Acetate and Ethanol, Ind. Eng. Chem. Res. 48 (2009) 9006-9012.

[6] A. B. Pereiro, J. M. M. Araújo, J. M. S. S. Esperança, I. M. Marrucho, L. P. N. Rebelo, Ionic liquids in separations of azeotropic systems - A review, J. Chem. Thermodyn. 46 (2012) 2-28. 
[7] K. N. Marsh, J. A. Boxall, R. Lichtenthaler, Room temperature ionic liquids and their mixtures - a review, Fluid Phase Equilib. 219 (2004) 93-98.

[8] A. Heintz, Recent developments in Thermodynamics and Thermo - physics of Non - Aqueous Mixtures Containing Ionic Liquids. A Review, J. Chem. Thermodyn. 37 (2005) 525-535.

[9] R. D. Rogers, G. A. Voth, Ionic Liquids, Acc. Chem. Res. 40 (2007) 1077-1078.

[10] Z. Lei, X. Xi, C. Dai, J. Zhu, B. Chen, Extractive Distillation with the Mixture of Ionic Liquid and Solid Inorganic Salt as Entrainers, AIChE J. 60 (2014) 2994-3004.

[11] Z. Lei, C. Dai, J. Zhu, B. Chen, Extractive distillation with ionic liquids: A review, AIChE J. 60 (2014) $3312-3329$.

[12] C. Dai, Z. Lei, X. Xi, J. Zhu, B. Chen, Extractive Distillation with a Mixture of Organic Solvent and Ionic Liquid as Entrainer, Ind. Eng. Chem. Res. 53 (2014) 15786-15791.

[13] D. Singh, R. K. Gupta, V. Kumar, Experimental Studies of Industrial - Scale Reactive Distillation Finishing Column Producing Ethyl Acetate, Ind. Eng. Chem. Res. 53 (2014) 10448-10456.

[14] T Qiu, P. Zhang, J. Yang, L. Xiao, C. Ye, Novel Procedure for Production of Isopropanol by Transesteri cation of Isopropyl Acetate with Reactive Distillation, Ind. Eng. Chem. Res. 53 (2014) 13881-13891.

[15] D. Bera, D. Lahiri, A. D. Leonardis, K. De, A. Nag. A Novel Azeotropic Mixture Solvent for Solvent Extraction of Edible Oils, Agricultural Engineering International: the CIGR Ejournal. Manuscript FP 06005. Vol. VIII. April, 2006.

[16] P. Susial, R. Susial, E. J. Estupiñan, V. D. Castillo, J. J. Rodríguez-Henríquez, J. C. Apolinario, Determination and thermodynamic evaluation of isobaric VLE of methyl acetate or ethyl acetate with 2-propanol at 0.3 and 0.6 Mpa, Fluid Phase Equilibria. 375 (2014) 1-10.

[17] R. Susial, P. Susial, High pressure vapor - liquid equilibria of methyl acetate or ethyl acetate with 2-propanol at 1.5 MPa. Experimental data and predictions, Chem. Eng. Res. Des. 102 (2015) 337-344.

[18] A. B. Pereiro, A. Rodríguez, Ternary (liquid + liquid) equilibria of the azeotrope (ethyl acetate + 
2-propanol) with different ionic liquids at $\mathrm{T}=298.15 \mathrm{~K}$, J. Chem. Thermodynamics. 39 (2007) 1608-1613.

[19] X. Shi, M. Wang, Isobaric vapor - liquid equilibrium for ethyl acetate - isopropanol - 1-octyl-3methylimidazolium tetrafluoroborate, Adv. Mater. Res. (Durnten-Zurich, Switz.) 641-642 (2013) 160-164.

[20] H. Renon, J. M. Prausnitz, Local composition in thermodynamic excess functions for liquid mixtures, AIChE J. 14 (1968) 135-144.

[21] E. Mullins, R. Oldland, Y. Liu, S Wang, S. I. Sandler, C. Chen, M. Zwolak, K. C. Seavey, Sigma-Profile Database for Using COSMO-Based Thermodynamic Methods, Ind. Eng. Chem. Res. 45 (2006) 4389-4415.

[22] E. Mullins, Y. Liu, A. Ghaderi, S. D. Fast, Sigma Profile Database for Predicting Solid Solubility in Pure and Mixed Solvent Mixtures for Organic Pharmacological Compounds with COSMO-Based Thermodynamic Methods, Ind. Eng. Chem. Res. 47 (2008) 1707-1725.

[23] L. Yang, S. I. Sandler, C. Peng, H. Liu, Y. Hu, Prediction of the Phase Behavior of Ionic Liquid Solutions, Ind. Eng. Chem. Res. 49 (2010), 12596-12604.

[24] F. Liu, L. Li, S. Yu, Z. Lv, X. Ge, Methanolysis of polycarbonate catalysed by ionic liquid [Bmim][Ac], J. Hazard. Mater. 189 (2011) 249-254.

[25] A. K. Burrell, R. E. Del Sesto, S. N. Baker, T. M. McCleskey, G. A. Baker, The large scale synthesis of pure imidazolium and pyrrolidinium ionic liquids, Green Chem. 9 (2007) 449-454.

[26] W. Hunsmann, Vaporization Equilibria of Formic Acid/Acetate Acid and Carbon Tetrachloride/Perchloroethylene Mixtures, Chem. Ing. Tech. 39 (1967) 1142-1145.

[27] VT-2005 Sigma Profile Database: A detailed tutorial for generating sigma profiles using Accelrys' Materials Studio v3.2 software package, Department of Chemical Engineering, Virginia Tech Blacksburg, VA 24060.

[28] Y. C. Kuo, C. C. Hsu, S. T. Lin, Prediction of Phase Behaviors of Polymer-Solvent Mixtures from the COSMO-SAC Activity Coefficient Model, Ind. Eng. Chem. Res. 52 (2013) 13505-13515. 
[29] P. Hernández, J. Ortega, Vapor - Liquid Equilibria and Densities for Ethyl Esters (Ethanoate to Butanoate) and Alkan-2-ol (C2-C4) at 101.32 kPa, J. Chem. Eng. Data. 42 (1997) 1090-1100.

[30] A. V. Orchillés, P. J. Miguel, F. J. Llopis, E. Vercher, A. Martínez-Andreu, Isobaric Vapor - Liquid Equilibria for the Extractive Distillation of Ethanol + Water Mixtures Using 1-Ethyl-3-methylimidazolium Dicyanamide, J. Chem. Eng. Data. 56 (2011) 4875-4880.

[31] Z. Zhang, A. Hu, T. Zhang, Q. Zhang, Q. M. Sun, D. Sun, W. Li, Separation of methyl acetate + methanol azeotropic mixture using ionic liquids as entrainers, Fluid Phase Equilib. 401 (2015) 1-8.

[32] Q. Li, X. Sun, L. Cao, B. Wang, Z. Chen, Y. Zhang, Effect of Ionic Liquids on the Isobaric Vapor Liquid Equilibrium Behavior of Methanol - Methyl Ethyl Ketone, J. Chem. Eng. Data. 58 (2013) $1133-1140$.

[33] Z. Zhang, A. Hu, T. Zhang, Q. Zhang, Z. Yang, W. Li, Isobaric vapor - liquid equilibrium for methyl acetate + methanol system containing different ionic liquids at $101.3 \mathrm{kPa}$, Fluid Phase Equilib. 408 (2016) $20-26$.

[34] A. E. Andreatta, M. P. Charnley, J. F. Brennecke, Using Ionic Liquids To Break the Ethanol - Ethyl Acetate Azeotrope, ACS Sustainable Chem. Eng. 3 (2015) 3435-3444.

[35] J. Li, X. Yang, K. Chen, Y. Zheng, C. Peng, H. Liu, Sifting ionic liquids as additives for separation of acetonitrile and water azeotropic mixture using the COSMO-RS method, Ind. Eng. Chem. Res. 51 (2012) 9376-9385.

[36] J. Dhanalakshmi, P. S. T. Sai, A. R. Balakrishnan, Study of Ionic Liquids as Entrainers for the Separation of Methyl Acetate-Methanol and Ethyl Acetate-Ethanol Systems Using the COSMO-RS Model, Ind. Eng. Chem. Res. 52 (2013) 16396-16405.

[37] A. Klamt, F. Eckert, COSMO-RS: a novel and efficient method for the a priori prediction of thermophysical data of liquids, Fluid Phase Equilibria. 172 (2000) 43-72.

[38] T. Banerjee, M. K. Singh, A. Khanna, Prediction of Binary VLE for Imidazolium Based Ionic Liquid 
Systems Using COSMO-RS, Ind. Eng. Chem. Res. 45 (2006) 3207-3219.

[39] M. R. Islam, C. Chen, COSMO-SAC Sigma Profile Generation with Conceptual Segment Concept, Ind. Eng. Chem. Res. 54 (2015) 4441-4454. 